\title{
Using Flipped classroom at University to improve the chemistry learning.
}

\author{
María del Mar López \\ Guerrero $^{\dagger}$ \\ Analytical Chemistry \\ University of Malaga \\ Malaga Spain \\ mmlopez@uma.es
Gema López Guerrero
Analytical Chemistry
University of Malaga
Malaga Spain
gemalog80@gmail.com

\author{
Pablo Montoro Leal \\ Analytical Chemistry \\ University of Malaga \\ Malaga Spain \\ montorolealplablo@gmail.com
}

Analytical Chemistry

University of Malaga

Malaga Spain

jcgm95@gmail.com

\author{
M. Auxiliadora López \\ Jiménez \\ Sevicio Centrales de Investigación. \\ University of Malaga \\ Malaga Spain \\ alj@uma.es
}

\begin{abstract}
The main objective of this paper was to improve the learning of Chemistry subject using Flipped classroom, because it makes class time more engaging. The lecture portion of General Chemistry courses in engineers degrees have been pushed outside the classroom using pre recording technology and steaming delivery of content, to make classes more interactive and participative. The Flipped classroom model has become one of the main topics in the higher education space in recent years thanks to improvements in technology.

This year, the Flipped classroom model with the chemistry students at Malaga State University has been begun experimenting with. Statistical significance of the data has shown, and proved with, that implementing the Flipped classroom model could not only benefit professors, but it could also help us adapt the classes to the various learning styles that exist among the students.

The study shows the results of surveys about student attitudes towards aspects of flipping the classroom.
\end{abstract}

\section{CCS CONCEPTS}

- $\mathrm{CCS} \rightarrow$ Applied computing $\rightarrow$ Education $\rightarrow$ E-learning

\section{KEYWORDS}

Flipped classroom, Chemistry, learning. Innovation at University 